\title{
The Representation of Euphemism in Moroccan Societal Discourse
}

\author{
Khalid Ouzguid \\ University of Lodz, Lodz, Poland \\ Email: linguist.psychology@outlook.com
}

How to cite this paper: Ouzguid, K. (2019) The Representation of Euphemism in Moroccan Societal Discourse. Open Journal of Social Sciences, 7, 243-251.

https://doi.org/10.4236/jss.2019.76020

Received: May 6, 2019

Accepted: June 24, 2019

Published: June 27, 2019

Copyright $\odot 2019$ by author(s) and Scientific Research Publishing Inc. This work is licensed under the Creative Commons Attribution International License (CC BY 4.0).

http://creativecommons.org/licenses/by/4.0/

\begin{abstract}
Individuals are more often involved in the process of exchanging information between one another; they could do so by a shared understanding of symbol systems, that is to say, sharing the same language. This communication process is a typically social and human phenomenon which occurs on a daily basis in anticipation of carrying social experiences to others. It is undeniable that communication may differ from one culture to another. Therefore, the way of speaking varies between individuals according to their social and education backgrounds. Yet, there is all likelihood that individuals tend to soften their language while conversing about certain topics. In this regard, one has to carefully select the efficient and appropriate vocabulary as not to hurt the listener(s). This strategy of softening the language is referred to as "euphemism". The frame of this descriptive paper focuses on casting light on the linguistic and cultural aspects of euphemism in the Moroccan language (Darija). The examples of Moroccan euphemisms which are used in this study are mainly collected from random Moroccan speakers either in the media or other social media. The description of Moroccan Darija implies that most Moroccans tend to play down certain words, or even tend to skip such words and use phonemic replacement, instead.
\end{abstract}

\section{Keywords}

Euphemism, Moroccan Arabic (Darija), Moroccan Discourse, Taboos. Politeness Face Strategies

\section{Introduction}

One cannot help but notice how Moroccan linguistic repertoire is enriched by its diversity in terms of the coexistence of various cultures as well as various languages. An overview of Moroccan linguistic and cultural background is due to be illustrated at the onset of this paper. It is widely believed that the Moroccan 
societal discourse treats taboos as topics which no-one should speak about in public, it is still governed by the word "Hshuma": the equivalent of "shame":

Hshuma (shame) which may be defined as the "loss of face in front of others". This loss of face may be occasioned behavior that contravenes social norms, breaks Islamic precepts, or abrogates personal obligations inside or outside the family ... The concept of Hshuma is fundamentally different from the Western notion of "guilt": whereas guilt is related to one's conscience telling him/her that something is wrong, the concept of Hshuma is related to one's awareness that others know that something is wrong (Sadiqi, 2003) [1].

This fear of losing one's face urges and motivates Moroccans to use different strategies in their daily conversations and small talks. This goes hand in hand with what Brown \& Levinson (1987) refer to as politeness strategies; they claim that speakers are likely to be polite because of the fact that they have the tendency to put their public image first, that is to say, being polite in one's talk is attributed to saving the face, otherwise there is all likelihood that one could lose their face only because of inappropriate manner of speaking. Similarly, Ghounane, Serir-Mortad \& Rabahi (2017) argued that one's face is treated as their honour which may represent the whole society, this is likely to be said about Muslim societies [2]. Therefore, politeness is urged to be used in their verbal interactions. According to Edwards and Guth (2010) [3], "Honour, dignity and self-respect are "sacred" concepts among Arabs since pre-Islamic times, and are considered taboos, which should not be abused by anybody" (p. 33), as cited in Ghounane, Serir-Mortad \& Rabahi (2017) [2]. When it comes to euphemism, speakers frequently soften the words that seem to be harsh, rude or unspoken about. Hence, this paper is of much interest to evoke expressions of euphemism in Moroccan language. The data was collected from various social platforms where Moroccan speakers were taking part in spontaneous discussions and conversations. These social platforms ranged from Youtube to Facebook as the main platforms that host authentic and casual talks among people. Yet, before embarking on the representation of euphemism in Moroccan Darija, it is worth commencing with some linguistic and historic backgrounds of the Moroccan kingdom.

\section{Moroccan Historic and Linguistic Background}

Throughout history, Morocco has been the target of many conquests like the Roman Empire, the Vandals, the Greek, the Byzantines, the Carthaginians, the Arabs, the French and the Spanish. All these nations have affected the Moroccan linguistics and created a multilingual profile. However, the crucial influence was made by the Arabic language due to the settlements of Arabs and due to their invasion of North Africa. Although "four main languages are used in Morocco: Standard Arabic, Moroccan Arabic, Berber [Tamazight], and French". (Fatima Sadiqi. 2003, p36) [1], it is worth mentioning that Tamazight and Moroccan Arabic (Darija) are the two means of communication on a daily basis. All Moroccans speak at least one language (either Tamazight or Darija), but most of 
them speak both.

It is true that Moroccans do not use direct and succinct words for naming taboos because of their conservative culture that is deeply rooted in the Islamic teachings. Yet, other expressions replace the unwanted or unpleasant words. This phenomenon is called euphemism. According to Hudson (2000, p. 261), euphemism is “ $\ldots$ the extension of ordinary words and phrases to express unpleasant or embarrassing ideas. The indirectness of form is felt to diminish the unpleasantness of the meaning. The words so extended are called euphemism, and some examples are ... pre-owned, and passed away" [4]. The presence of Euphemism in Moroccan Darija is represented through media in many expressions and phrases, which I am going to investigate and tackle with many examples and details.

\section{Examples of Euphemism in the Moroccan Culture}

One cannot help but notice that most North African countries in general share some practices of using euphemism in their everyday conversations; this could be attributed to the fact that these countries share similar culture and similar faith and similar linguistic background, too.

\subsection{Black Color and "Jnun"}

The Black color is related to bad luck in the Moroccan culture, as well as in other North African countries, which may share this practice from the roots of religion. Many people believe that black is a bad omen, especially when people come across sort of black objects in the morning. This is illustrated by Westermarck (2014, p. 15) by stating that: “... The color black is by itself a bad omen and a source of evil, no doubt on account of the gloomy impression it makes on the human mind, which is averse to darkness" [5].

It is noticeable that there are many phrases used by Moroccans with black color as a bad omen. For example: "Waynni àla nhar khal" (what a black day!) This phrase is used to express how tough and long a day is/was, mainly a day full of simultaneous and continual problems that emerge from each and every different situation. Here the day is presented as dark, which is metaphorically used to indicate difficulties people encounter during daylight. Another example is the phrase "Mosiba kehla" the equivalent of "a black trouble" in English. It is used in two different contexts: the first one is when someone talks about a real trouble or a situation that requires an external help from relatives or acquaintances. It may indicate that it has no prospective solution. The second usage applies to the way in which someone is described as a troublesome person.

Moroccans do not approve black color not only because it is a bad "fàal" omen, but also because it is the color of "Jnun"; meaning goblins, ghosts and spirits. Indeed, Moroccans try to ward off the devil by saying "Bismi Allah ar Rahman ar Rahim", which means in the name of Allah the merciful and the compassionate. It is widely believed that repeating this saying, which is taken 
from the holly book, no-one would be harmed.

"Jnun" the plural (it is always pluralized to talk about the goblins as superpower creatures as it is believed that they are able to see humans while they remain invisible.) while the "Jenn" is singular. At any rate, "Jnun" as a native word itself is avoided in everyday conversations. According to Mateo Dieste, "the term "jinn" is avoided, so as not to evoke them". Still, they are euphemized as the people of "Bismi Allah Arrahman Arrahim" or simply by referring to them as "those others." Not only is this phrase used but also other phrases and names as stated below:

Different names for different Inun: Rohani, a jinn who lives between the earth and the sky, l-mluk, the kings of the jnun; sidna, "our lord"; rjal al-hafiya, "the man of the hidden/occult", or shaytan, afrit, formulate used to refer to the devil. Information consulted often also use the expression l-ariah, "airs"/winds in an implicit reference to jnun or demons" (Mateo Dieste, 2013, p. 262) [6].

As far as Moroccan Darija is concerned, all the latter words used to mean goblings are euphemized words, which indicate that these kinds of superpower creatures (jnun) live in the air and water. Here the dichotomy of "US" versus "THEM" shifts from its ordinary application where two parts belong to the same species (humans) to another part which is the metaphysical and powerful "other". Notice here the submission of humans "US" to superior "THEM".

The Jnun can be found whenever there is water, and the potentially hazardous places are exactly the same in Europe as in the Maghreb [Morocco or North African countries]. Indeed, one young man told me that a European country like Holland is home to even more jnun than Morocco, because of the amount of water to be found there. (Mateo Dieste, 2013, p. 263) [6].

However, when it comes to black-skinned, people do not turn to them as black due to its racist connotation based on the skin color. In this regard, s/he is addressed as "Lwiyen", which is the equivalent of colorful in English. There is also another expression, which is commonly used among well-educated people and dark skin people themselves. Thus, black skin is euphemized as "wahd ssmiyer", which literally means brown skin. It sounds less embarrassing for the speakers to use brow skinned or colorful rather than strong black skin.

However in the media, there is a slight comment on how people are referred to based on their color of skin when it comes to Africans. It is true that Morocco is an African country which embraces diversity and accepts differences; therefore, I daresay that Moroccan dark skinned people are never differentiated in the Media. As for Africans, they are usually represented as "Africans from the southern Sahara". It suffices to say this phrase to link the connotation and the intention of the speaker/writer.

\subsection{The Representation of Women in Moroccan Discourse}

The presence of women in Moroccan culture is always associated with men. "The terminology used to refer to girls and women is significant. Adjectives like mahkuma "governed", mziyyra "controlled", taht lahkam "under control", mrat 
rrajel "woman of a man", as opposed to bent zzenqa "girl of the street", and the Berber expression ddaw ufus "under the hand, controlled" (Sadiqi, 2003) [1]. Although Moroccan women nowadays rub shoulders with men in many domains and fields that until recently have been male-dominated, and somehow they assert themselves as active members of society, many people consider them incomplete without men. In most cases, referring to them is never direct because of men domination in Moroccan culture:

Moroccan national history has been officially recorded by men. The images of women in it are created from a male's point of view. Accordingly, gender, class, and regional differences have been blurred in official accounts. In these views, women's roles are either ignored or made secondary to men's (Fatima Sadiqi, 2003) [1].

Thus, many euphemisms are used to replace the female gender. Here are some authentic examples: When a person wants to ask about his friend's wife, he should not dub her name using a direct question like: "how is your wife doing?" instead, it is advisable to sweeten the conversation and say for instance: "kidayra mulat ddar?" how is the lady (the owner) of the house; the owner here is used metaphorically and does not mean that the house belongs to the wife. Another expression is "kidayrin lwlidat?" how are your children doing? Here, even it seems that the person is asking about children but it is not the case. What should be understood is that it is beyond what western people might understand. It may sound strange but this euphemism works also for those who do not have children yet. This expression is used to show respect for the husband. Otherwise, he would feel embarrassed among his colleagues. The well-educated and affluent people may also feel embarrassed when it comes to asking about their acquaintances' wives in direct discourse. Therefore, instead of using one of the previously mentioned euphemisms for a wife, they find themselves quite relaxed using the French word "Madame". Thus, "how is your wife doing?" might be like: "Kidayra L-madame dialk?” or simply "Kidayra L-madam?”

On the flip side of the representations of women in its sociolinguistics perspective, there is the other side represented in the media, I would differentiate between the representations of women in two aspects of media. Newspapers and audio/visual media (radio, TV etc.). The former is believed to use a benign discourse which does not discriminate the role of women in the Moroccan society. Women are independent and have full access to rights which men have. However, the later (TV for example) is still using some negative representations of women from society as mentioned above.

\subsection{Taboos}

A taboo has been defined as "a strong social prohibition (urban) relating to any area of human activity or social custom declared as sacred and forbidden" (Wikipedia): "any prohibition resulting from social or other conventions ... ritual restriction or prohibition, especially of something that is considered holy or unclean”. (C.E.D, p. 1554) [7]. 
Adams and Newell (1994, p. 12) describe taboos as "an infinite variety of things that go bump in the night" [8]. These taboos mainly include; private parts, bodily functions, sex, anger, drunkenness, madness, death, fear, God and so on and so forth.

Taboos are presented in many cultures all over the world. They might differ from one nation to another due to beliefs, geography, language, and religion ... etc. For example, a woman who smokes a cigarette in western countries is accepted as a member of society who has full rights as men do. While in Moroccan culture, people may label a female smoker as a prostitute using different euphemisms. So how do Moroccans euphemize prostitutes in their everyday life conversations?

It is true that most of Moroccans feel shame to mention the exact word "Qahba" for prostitute in their everyday conversations. It is due to the fact that "night ladies" are unwanted and they carry a social stigma in which people turn their backs. Therefore, "Bnat zenqa”, or street girls for English equivalent is common expression used to refer to them. But from my perspective, this phrase is still embarrassing, rude, and too strong for some Moroccans who find themselves among mixed gender groups, as in this case the girls would feel annoyed if not disrespected. However, "Lhariba" as another alternative is less offensive and serves the purpose. In English, it literally means a runaway girl, who is a prostitute and does not live with their families any longer, or she lives in isolated brothels or rents a single room in the city suburbs, where prospective clients seek the appropriate moment for making deals away from the authorities' eyes.

In religious discourse, the word "baghiya" is borrowed from standard Arabic. "A quahba [the equivalent of whore in English] or prostitute is called 'baghiya', which indicates a woman who is 'desirous of men"' (Westermarck, 2014) [5].

The media in all its aspects tends to use the standard Arabic naming due to the fact that there is some legislation which follows Islamic rules.

I also would like to emphasize that a single mother is not embraced in the Moroccan culture, so no wonder that we cannot find a single word for it in Darija. Thus, a son who is born out of wedlock is referred to as "wald Al-hram" child of forbidden, or "wald zanqa" a child of street; these phrases are euphemized and they replace the phrase "wald Al-qahba" which literally means the son of a bitch, in some regions of north, one might hear "Awlad as-souq" sons of souk (traditional market).

"Virgin mothers" is how literally referred to in the media. It is controversy but Moroccan society is still governed by moderate Islamic constitution, it is understandable that the change takes time and some linguistic naming will take over others.

\subsection{How Toilet Is Euphemised}

A lot of people may not be comfortable to use the direct word "toilet". That could be true, namely in western cultures. In English, people do not use toilet itself but they use other words and phrases such as: 
1) I am going to the rest room.

2) Where can I find public conveniences?

3) I am going to powder my nose. (Usually used by girls).

Also, Moroccans use different words to lessen the embarrassment of the speaker. These are some examples:

1) "Bit Ar-raha" the equivalent of rest-room in English.

2) “Bit Al-ma” which means waterloo.

3) "Dar Al-wodoe" literally means ablution-room ...

It is worth mentioning that jargon plays a vital role in euphemism, at least among Moroccan teenagers, when a person indicates that he/she is going to use the toilet, they turn to others like in these examples below:

As shown in Table 1, teenagers have the tendency to use different expressions to indicate visiting a toilet so as to avoid direct utterances. It should be noted that most above examples are likely to be used by males than females. However, all of the examples are still used in a soften way.

\subsection{Death}

The death of a family member is the saddest news one could ever hear. That is why Moroccans avoid saying that someone has died. Therefore, expressions from religious vocabulary are quite often used for example: "Bghah Allah" or "Ddah Allah" (Allah preferred him above the others) or "Allah has taken him", "Mcha mskin" poor one! He/she has gone, "wsal L-ajal dialo" his deadline has approached him/her or "Allah iwalih birahmati Allah" May Allah has mercy on him. While English speakers use other euphemisms like: Departed our world, passed away and pushing up daisies. "Was put to sleep" is used instead of euthanized. In similar vein, Ghounane, Serir-Mortad \& Rabahi (2017) carried out a research on how Algerians refer to death in their everyday communication, the study covered 200 participants of both gender. It revealed that the vast majority are likely to soften and avoid using the word "death" directly [2].

\subsection{Other Societal Euphemisms}

It should be noted that while most of these euphemisms are used among adults, teenagers on the other hand are unlikely to soften their language when they tend to communicate with their counterparts. The table below shows various euphemisms that are likely to be used on a daily basis by most Moroccans when speaking to others.

As Table 2 illustrates other different factors of euphemism expressions in Moroccan daily discourse, it is worth stressing the fact that such expressions are likely to be used among other Maghreb countries because of the cultural similarities. In fact, sexual organs are replaced by other objects of everyday use. While western people use balls to refer to males physical organs, Moroccans are likely to use "one's eggs" instead. Similarly, in Hijazi Dialect, they use the words "daldool" which means "dangling objects" Almoayidi (2018). Having a sexual intercourse is rarely used directly among speakers, however they are more 
Table 1. Teenagers' jargon referring to visiting toilet.

\begin{tabular}{cc}
\hline Euphemised expressions in Darija & Their equivalent in English \\
\hline "Ghanmchi nrash a-lma" & I will go to spray water \\
"Nemchi àla brra" & I am going outside \\
"Nemchi nkhllas lkridi" & I am going to pay off my debts \\
\hline
\end{tabular}

Table 2. Other different Moroccan euphemisms.

\begin{tabular}{cc}
\hline Euphemised expressions in Darija & Their equivalent in English \\
\hline "Mafhalouch" instead of poor & It is not within his means/reach \\
"Hbsat lwlada" instead of abortion & $\begin{array}{c}\text { She stopped conceiving } \\
\text { (pregnancy termination) }\end{array}$ \\
"Mra Aamra" instead of referring to how big she is. & She is a full woman. \\
"Aàyyan chwiya" instead of sick & A bit tired \\
"ssamta ltaht" instead of sexual organs & Below the belt
\end{tabular}

probable to avoid talking about it, or else use some alternative phrases such as "we did that thing before sleeping". This is what Almoayidi (2018) mentioned in his paper about the use of euphemism in Hijazi Dialect, he stated that a male could say that he had a "red night" to mean that he had sex with his wife. Also he argued that a virgin woman is always referred to as "a sealed girl". All these phrases are used in order to avoid direct words [9].

\section{Conclusion}

This paper has covered a wide range of euphemisms that are used in Moroccan daily discourse. The descriptive study was mainly focused on Moroccan dialect (Darija). As a general principle, it reveals that most utterances among speakers are likely to be softening when it comes to taboos and other topics which are regarded as unwanted or unspoken about. Such topics range between death, sex, women, and many others. As explained above, it is of paramount importance to note that the use of euphemism in Moroccan Darija could be attributed to the influence of Arabic culture in general and Islam in particular. Equally important, the intention of keeping one's face increases the probability of resorting to euphimized words and phrases.

\section{Conflicts of Interest}

The author declares no conflicts of interest regarding the publication of this paper.

\section{References}

[1] Sadiqi, F. (2003) Women, Gender and Language in Morocco. Brill Academic Publishers, Boston and Leiden.

[2] Ghounane, N., Serir-Mortad, I. and Rabahi, H. (2017) Politeness Strategies Em- 
ployed towards Linguistic Taboos in Tlemcen Society. Open Journal of Modern Linguistics, 7, 217-228. https://doi.org/10.4236/ojml.2017.75016

[3] Edwards, L. and Guth, S. (2010) Verbal Festivity in Arabic and Other Semitic Languages. Deutsche Morgenlandiche Gesellschaft Harrassowitz Verlag.

[4] Hudson, G. (2000) Essentials of Introductory Linguistics. Blackwell Publishers, USA, Stockwell, P. Sociolinguistics. Rutledge, London.

[5] Westermarck, E. (2014) Ritual and Belief in Morocco: Vol. II (Routledge Revivals). https://doi.org/10.4324/9781315850436

[6] Dieste, M. (2013) Health and Ritual in Morocco: Conceptions of the Body and Healing Practices, Boston. https://doi.org/10.1163/9789004234482

[7] Taboos (n.d.). In Wikipedia. https://en.wikipedia.org/wiki/Taboo

[8] Adams, P. and Newell, P. (1994) The Penguin Book of Australian Jokes. Penguin, Ringwod, Victoria.

[9] Almoayidi, K.A. (2018) Euphemism as a Communicative Tool: A Descriptive Study of Hijazi and Southern Region Dialects Spoken in Saudi Arabia. Open Journal of Modern Linguistics, 8, 1-8. https://doi.org/10.4236/ojml.2018.81001 